\title{
Skin changes in chronic lymphatic filariasis
}

Haran Burri $^{1^{\star}}$, Louis Loutan ${ }^{2}$, V. Kumaraswami ${ }^{3}$ and V. Vijayasekaran ${ }^{4}{ }^{1}$ Medical Clinic 1 and ${ }^{2}$ Travel and Migration Medicine Unit, Department of Community Medicine, University Hospital, Geneva, Switzerland; ${ }^{3}$ Tuberculosis Research Centre, Madras, India; ${ }^{4}$ Clinical Pharmacology Unit, Madras Medical College and Government Hospital, Madras, India

\section{Abstract}

Seventeen men and 31 women with unilateral lower limb lymphoedema attributed to chronic lymphatic filariasis were examined in the filarial out-patient clinic of the Government General Hospital, Madras, India. Skin changes such as skin fold thickening, hyperkeratosis, hypo- or hypertrichosis, pachydermia, pigmentary changes, chronic ulceration, epidermal and sub-epidermal nodules, and clinical intertrigo were observed and compared between the different lymphoedema grades. These lesions are not specific to chronic lymphatic filariasis, and have been described in other conditions displaying lymphostasis. 'They are thought to be favoured by secondary infections, which should be dealt with appropriately to prevent the progression of the disease and the onset of elephantiasis.

Keywords: filariasis, Wuchereria bancrofti, skin changes

\section{Introduction}

Lymphatic filariasis is a disfiguring disease caused by the mosquito-transmitted nematodes Wuchereria bancrofti, Brugia malayi and B. timori. It was estimated in 1992 that almost 80 million individuals were infected world-wide (WHO, 1992).

Similarly to leprosy, the disease exhibits striking skin changes without being in itself a threat to human life. The lymphoedema and skin lesions associated with this disease, as well as having social consequences, favour the development of secondary infections which further contribute to the pre-existing lymphatic damage. So far, to our knowledge, there has been no study observing systematically the various skin lesions related to chronic lymphatic filariasis. The aim of this study was to describe clinically the skin lesions associated with chronic lymphatic filariasis and the different grades of lymphoedema.

\section{Materials and Methods \\ Study population}

Seventeen men and 31 women (17 to 68 years of age, mean $46.5 \pm 14.4$ years) were selected from about $200 \mathrm{pa-}$ tients consulting the filariasis out-patient department of the Government General Hospital, Madras, India between 25 November and 17 December 1992. As patients with chronic lymphatic filariasis are usually amicrofilaraemic and there is no currently available test to prove active filarial infection, the diagnosis of filariasis was established on clinical grounds.

All patients were living in the urban area of Madras (known to be endemic for bancroftian filariasis) and displayed lower limb lymphoedema. Only patients displaying unilateral lower limb disease were considered, the unaffected limb acting as a control for comparing the features examined. Individuals manifesting illnesses prone to be held responsible for oedema formation (e.g., cardiac and chronic venous insufficiencies, hepatic or renal disease, etc.) were excluded. The same applied to those who had undergone surgery for lymphoedema and skin lesions, or who had experienced bouts of lymphangitis during the month preceding the examination, since the local skin status would have thereby been altered.

\section{Clinical eqaluation}

A brief history was obtained from each patient using a standardized questionnaire. Clinical examination evaluating the lymphocdema and skin changes was performed in each case.

Lymphoedema. The lymphoedema was classified into 3 grades according to the International Society of Lymphology (WHO, 1992). Grade I: mostly pitting oedema, spontaneously reversible on elevation; grade II: mostly

^Author for correspondence. non-pitting lymphoedema, not spontaneously reversible on elevation; grade III (elephantiasis): grade II lymphoedema with dermatosclerosis and papillomatous lesions (Fig. 1).

Skin fold thickening. This was measured to the nearest millimetre by pinching the skin over the foot dorsum with skin callipers. Dermal oedema was dispersed by firm pressure during $5 \mathrm{~s}$ before the measurement in order to assess the thickening due to tissue proliferation alone. The foot region was chosen for this measurement since it has the advantage of manifesting the earliest tissue changes due to its dependency (KAR, 1990). The skin fold thickness on the foot dorsum of the healthy limb was subtracted from the corresponding measurement of the oedematous limb so as to obtain the amount of thickening. The skin fold thickening in cases exhibiting considerable skin sclerosis was difficult to evaluate and was therefore arbitrarily considered to be $18 \mathrm{~mm}$.

Other skin changes. The pilosity and pigmentation were compared with the corresponding skin surface of the control limb. The presence of hyperkeratosis, pachydermia, cutaneous nodules, ulcerations and clinical intertrigo was also evaluated.

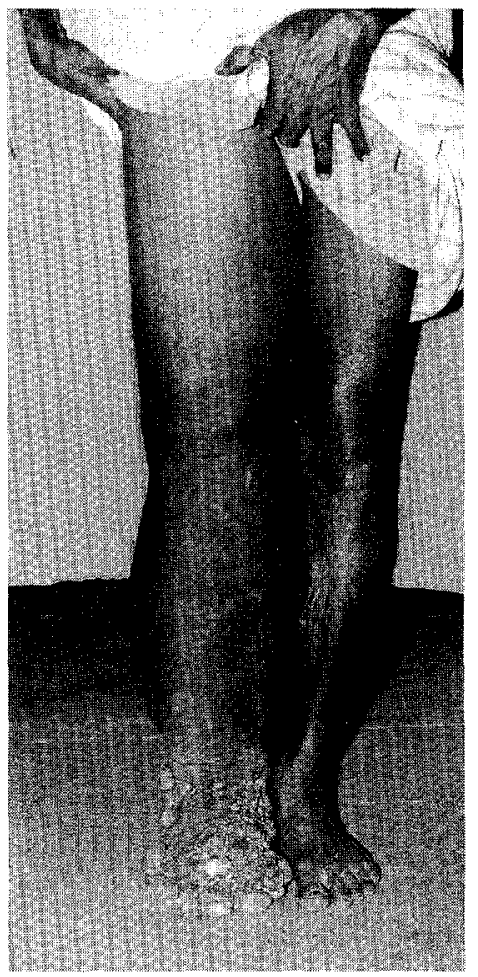

Fig. 1. Unilateral grade III lymphoedema (elephantiasis) of the right lower limb. 


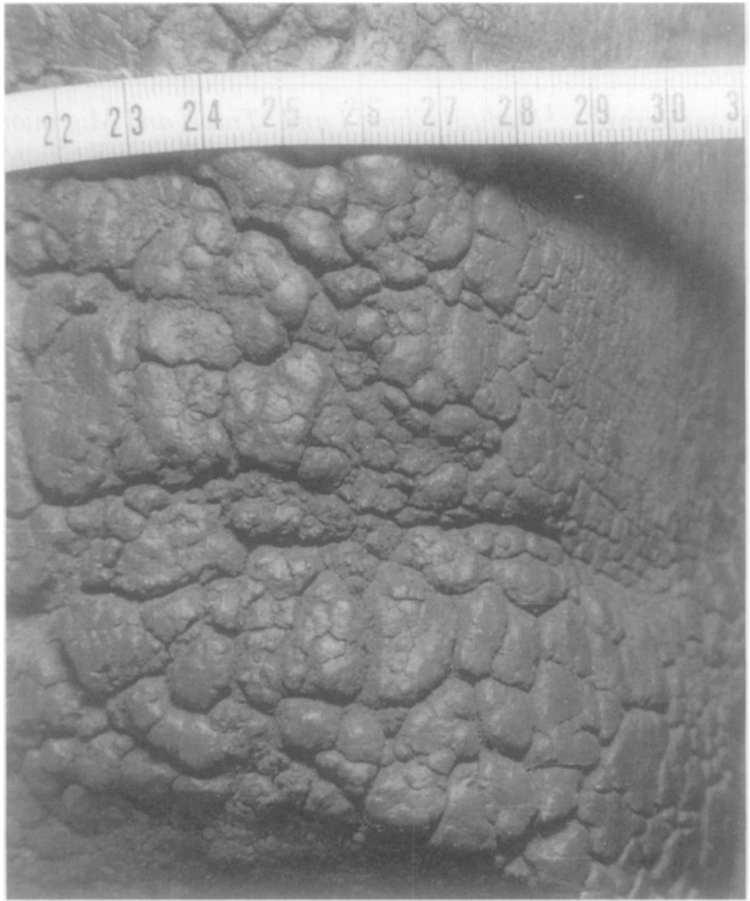

Fig. 2. Extreme hyperkeratosis over the anterior tibial region. tous regions was comparable to that of the control limb in 34 cases $(71 \%)$. However, post inflammatory hyperand hypopigmentation were seen in $11(23 \%)$ and $3(6 \%)$ of the cases, respectively.

Epidermal nodules. These were found in 7 of the 13 cases of grade III oedema. These nodules, firm in consistency and varying in diameter from under $1 \mathrm{~mm}$ to over $6 \mathrm{~cm}$, were asymptomatic in all cases. There tended to be a loss of pigmentation of the larger nodules (Fig. 4). All cases had the nodules distributed predominantly over the metatarso-phalangeal and/or anterior tibio-tarsal regions. The nodules were sometimes aligned over skin folds resulting from the creasing of oedematous tissue and near interdigital clefts (Fig. 5). The plantar regions were spared from any verrucous changes.

Subepidermal nodules. These asymptomatic lesions were present in virtually all the patients (12 of 13$)$ with grade III oedema. They varied in size from under a millimetre to plaques several centimetres in diameter resulting from the merging of groups of nodules (Fig. 6). They were distributed over the entire oedematous leg and foot (sparing the plantar surfaces).

Secondary infections. Clinical interdigital intertrigo of the oedematous lower limb was observed in 24 of the cases $(50 \%)$ (Fig. 5). Musca domestica, causing accidental myasis (BEAver et al., 1984), was found in one case, with the maggots within ulcerations over epidermal nodules.

Chronic ulcerations. Four patients with grade III oedema presented chronic ulcerations over the foot dorsum of over one year's duration.

Table. Summary of the skin changes found in the filariasis patients

\begin{tabular}{|c|c|c|c|c|c|c|c|c|c|c|c|}
\hline \multirow{2}{*}{$\begin{array}{l}\text { Grade of } \\
\text { oedema }\end{array}$} & \multirow{2}{*}{$\begin{array}{c}\text { No. of } \\
\text { patients }\end{array}$} & \multicolumn{5}{|c|}{ Pilosity } & \multicolumn{2}{|c|}{ Pachydermia } & \multicolumn{3}{|c|}{ Keratosis } \\
\hline & & Increa & sed & Unch & ed & Decreased & Present & Absent & Norma & $\mathrm{l} \mathrm{Hy}$ & erkeratosis \\
\hline $\begin{array}{l}\text { I } \\
\text { II } \\
\text { III } \\
\text { Total }\end{array}$ & $\begin{array}{l}25 \\
10 \\
13 \\
48 \\
\end{array}$ & $\begin{array}{r}1 \\
3 \\
2 \\
6(12 \cdot 5 \\
\end{array}$ & & $36(7$ & $\begin{array}{l}4 \\
7 \\
5 \\
75 \%)\end{array}$ & $\begin{array}{c}0 \\
0 \\
6 \\
6(12 \cdot 5 \%) \\
\end{array}$ & $\begin{array}{c}3 \\
4 \\
2 \\
9(19 \%)\end{array}$ & $\begin{array}{c}22 \\
6 \\
11 \\
39(81 \%)\end{array}$ & $\begin{array}{r}20 \\
4 \\
1 \\
25(52 \%\end{array}$ & & $\begin{array}{c}5 \\
6 \\
12 \\
3(48 \%) \\
\end{array}$ \\
\hline $\begin{array}{l}\text { Grade of } \\
\text { oedema }\end{array}$ & $\begin{array}{c}\text { No. of } \\
\text { patients }\end{array}$ & Increased & & $\begin{array}{l}\text { tatior } \\
\text { nged }\end{array}$ & Decreased & $\begin{array}{r}\mathrm{N} \\
\text { d Epidermal }\end{array}$ & $\begin{array}{l}\text { dules } \\
\text { Subepidermal }\end{array}$ & $\begin{array}{l}\text { Inte } \\
\text { Present }\end{array}$ & $\begin{array}{l}\text { rigo } \\
\text { Absent }\end{array}$ & $\begin{array}{r}\text { Ulce } \\
\text { Present }\end{array}$ & $\begin{array}{l}\text { ation } \\
\text { Absent }\end{array}$ \\
\hline $\begin{array}{l}\text { II } \\
\text { III } \\
\text { Total }\end{array}$ & $\begin{array}{l}25 \\
10 \\
13 \\
48 \\
\end{array}$ & $\begin{array}{c}3 \\
1 \\
7 \\
11(23 \%) \\
\end{array}$ & & $\begin{array}{c}22 \\
8 \\
4 \\
(71 \%) \\
\end{array}$ & $\begin{array}{c}0 \\
1 \\
2 \\
3(6 \%) \\
\end{array}$ & $\begin{array}{c}0 \\
0 \\
7 \\
7(15 \%) \\
\end{array}$ & $\begin{array}{c}0 \\
0 \\
12 \\
12(25 \%) \\
\end{array}$ & $\begin{array}{r}6 \\
6 \\
12 \\
24(50 \% \\
\end{array}$ & $\begin{array}{c}19 \\
4 \\
1 \\
24(50 \%) \\
\end{array}$ & $\begin{array}{c}1 \\
0 \\
4 \\
5(10 \%) \\
\end{array}$ & $\begin{array}{c}24 \\
10 \\
9 \\
43(90 \%) \\
\end{array}$ \\
\hline
\end{tabular}

\section{Results}

A summary of the results is shown in the Table.

Skin fold thickening. All the cases examined displayed skin fold thickening of the oedematous limb, compared to the healthy limb. Patients with grade I oedema had a mean thickening of $3 \pm 1.8 \mathrm{~mm}$ (range 1 to $7 \mathrm{~mm}$ ), those with grade II oedema had a mean of $12 \pm 3.6 \mathrm{~mm}$ (range 8 to $18 \mathrm{~mm}$ ), and cases of grade III oedema had a mean of $15 \pm 3.9 \mathrm{~mm}$ (range 6 to $>18 \mathrm{~mm}$ ).

Relative pilosity. In 36 cases (75\%), the pilosity was similar to that of the control limb. All 6 patients (12.5\%) showing regional hypotrichosis had grade III oedema. Hypertrichosis of the afflicted limb was present in 6 patients ( $12.5 \%$ overall) in all 3 oedema categories.

Pachydermia. Accentuation of the epidermal creases was present in 9 cases $(19 \%)$, being usually most pronounced over the anterior tibio-tarsal region and foot dorsum.

Hyperkeratosis. Twenty-three patients (48\%) presented hyperkeratosis over the oedematous limb. The skin surface varied from being slightly roughened to forming a layer several millimetres thick (Fig. 2). In 2 of these patients, there was severe papillomatosis over the borders of the plantar regions, with keratin horns imparting a 'mossy' appearance to the foot (Fig. 3).

Pigmentation. The overall pigmentation of the oedema-

\section{Discussion}

Lymphatic filariasis has a wide spectrum of clinical presentations (PARTONO, 1987). Individual variations in the immunological response to the parasite are believed to influence the outcome of the disease (SENEGUPTA et $a l ., 1986$; PISSENS et al., 1987; OTTESEN, 1992). Asymptomatic subjects are usually microfilaraemic, and produce cytokines that have anti-inflammatory effects. On the other hand, patients with symptoms such as acute adenolymphangitis or chronic lymphoedema are usually amicrofilaraemic, and react to the parasite antigens by a highly inflammatory response, which may bring about lymphatic lesions. Furthermore, it is believed that the lymphatic-dwelling parasite may directly damage the lymphatic vessels (CASE, 1991; OLSEWSKI, 1991; WHO, 1993), and may produce mediators which inhibit the contractility of lymphatic vessels.

The skin changes found in lymphatic filariasis are non-specific and have been found in other conditions showing chronic lymphostasis such as primary lymphoedema and carcinomatous lymphangitis, or in infirm patients contined to a chair in whom the combination of immobility and limb dependency brings about lymphoedema of the lower limbs, sometimes accompanied by nodular skin lesions (RICHARDS, 1981; MORTIMER, 1990). The skin changes in these conditions have popu- 


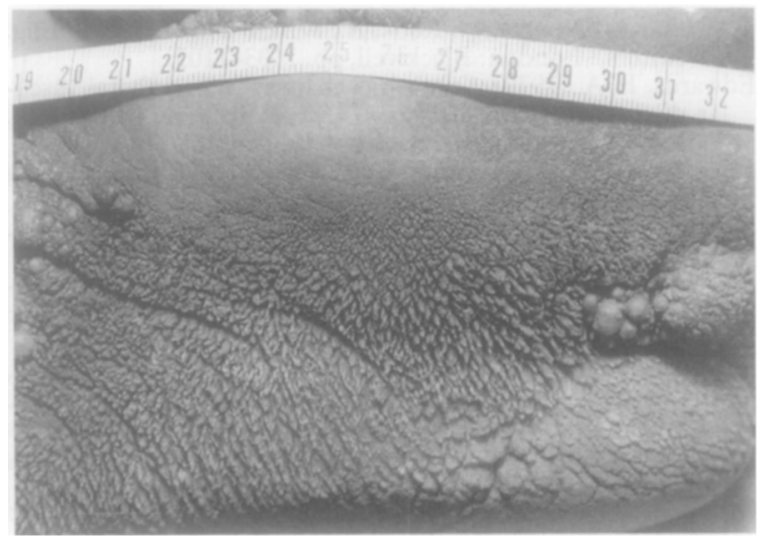

Fig. 3. Severe papillomatosis over the borders of the plantar region, with keratin horns.

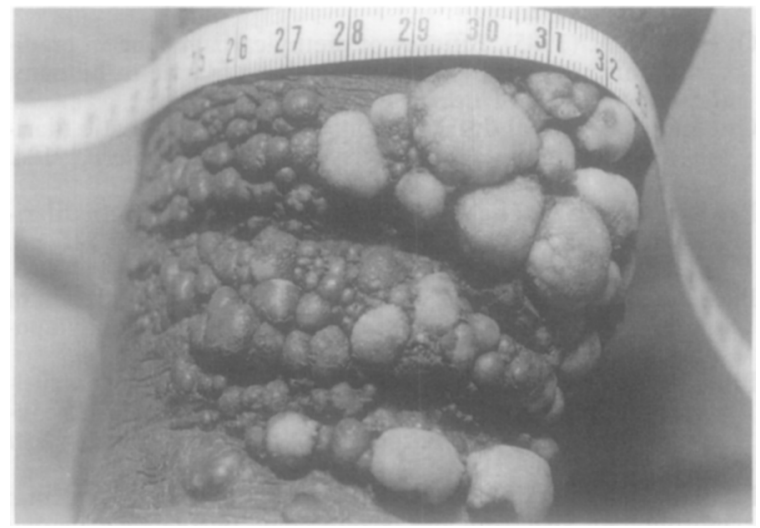

Fig. 4. Epidermal nodules over the distal anterior tibial region with pigmentary loss of the larger nodules.

larized terms such as 'elephantiasis verrucosa nodosa' or 'mossy foot' (CHAMPION, 1979; RICHARDS, 1981).

Even though patients with chronic lymphatic filariasis are often depicted with grossly oedematous limbs and unsightly skin lesions, it can be seen that less than one-third (13) of the 48 patients attending the filarial clinic presented grade III oedema (elephantiasis) with nodular skin lesions. Furthermore, this figure may be disproportionately high compared to the general population of symptomatic filarial patients, since the cases were chosen from a hospital setting.

Skin fold thickening was a feature common to all the patients examined. Histopathological examination of chronic lymphoedematous skin has shown collagen deposition in the dermis and subcutaneous tissues as well as epidermal thickening, hyperkeratosis and acanthosis (RYAN et al., 1986; OLSEWSKI et al., 1993). Various theories have been put forward to explain the lipodermatosclerosis found in lymphoedema. Proteins in the interstitial fluid, having perhaps undergone alterations due to lymphostasis, may act as mediators for fibroblasts and inflammatory cells. Secondary infections are also believed to contribute to the increased collagen deposition (CASLEY-SMITH, 1985; PILlaR, 1990).

It is possible that the protein-rich lymphoedema and the presence of subacute inflammation leading to local vasodilation may favour hypertrichosis, as was found in some of the patients we examined. In the more advanced cases, dermatosclerosis may later lead to atrophy of the follicles and thus to hypotrichosis.

Pigmentary changes were also found, consisting of diffuse post-inflammatory hyperpigmentation and hypopigmentation. Specific changes, such as the leopard skin' depigmentation seen in onchocercal filariasis

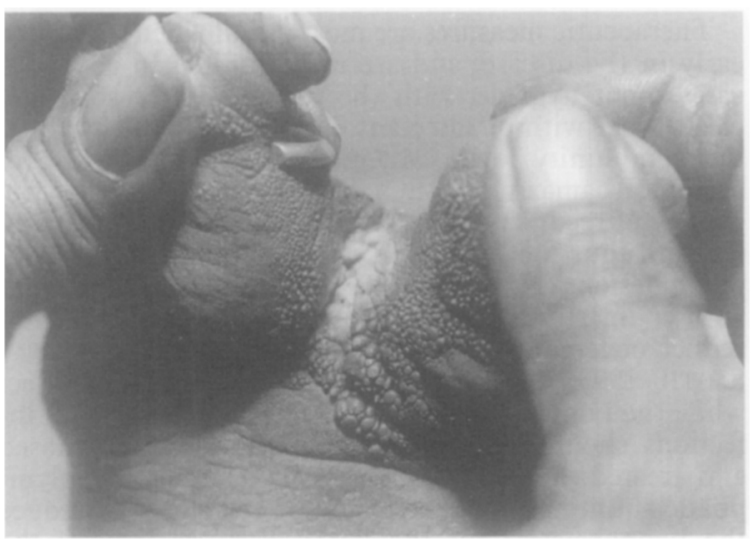

Fig. 5. Epidermal nodules over the toe clefts with interdigital intertrigo.

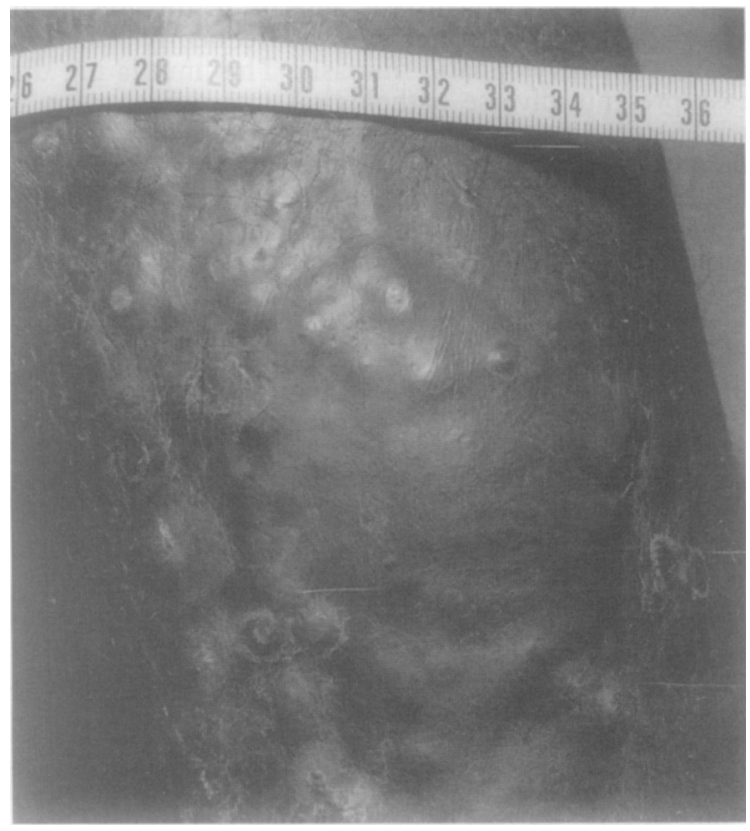

Fig. 6. Subepidermal nodules over the anterior tibial region.

(MURDOCH et al., 1993), were, however, absent.

It is thought that the verrucous growths found in elephantiasis are favoured by secondary infections intervening in the context of chronic lymphostasis (EDWARDS, 1979). This may perhaps explain why these epidermal nodules were found predominantly over the phalangeal regions and over skin folds, where microbial densities would presumably be higher.

Interdigital intertrigo was found in half the patients examined. Since the lymphatic system plays a major role in the elimination of pathogens, any compromise of its functional capacity would subsequently favour secondary infections (OLSEWSKI, 1991). Furthermore, the oedematous swelling of the toes and the presence of tightly packed skin nodules create niches for bacterial or fungal growth as well as for the development of infections such as myasis. Chronic ulceration may result from the repeated trauma of a cumbersome oedematous limb and impeded healing, providing access for secondary infections. These would in turn further damage the lymphatic system, thus constituting a vicious circle. For these reasons, the filarial leg should be considered similarly to the diabetic foot concerning preventive care, with due importance being given to foot hygiene and the prevention of trauma. 
Therapeutic measures are most useful when instigated early in the disease, and are more limited in advanced cases. Foot hygiene, with the regular use of soap and clean water with disinfectant, has proved to be useful at the community level (MCGREGOR, 1994). The use of diethylcarbamazine (DEC) therapy reduces the frequency of recurrent adenolymphangitis due to the parasite and thus the likelihood of developing chronic lymphatic lesions (OTTESEN, 1985; WHO, 1992). Treatment with coumarin (5,6-benzo- $\alpha$-pyrone) has been shown to reduce oedema in all grades of lymphoedema (CASLEYSMITH, 1993). Elastic bandages have a beneficial effect while the lymphoedema is still reversible. Secondary infections should, of course, be appropriately diagnosed and treated. Surgical interventions such as adenolymphatic shunting procedures may be attempted to reduce the lymphostasis, hut the duration of patency of the shunt remains unknown (WHO, 1992). Tangential excision of the epidermal nodules with skin grafting can be undertaken in advanced cases.

Even though elephantiasis appears in diseases of diverse aetiology, it is probably most frequently associated globally with lymphatic filariasis. This mutilating disease presents diverse pathological intricacies, many of which remain to be elucidated. Future research in this field will, hopefully, help us understand and control the mechanisms which bring about the suffering of millions of people around the world. In the meantime, preventive measures such as local hygiene, prevention and treatment of secondary infections, and mechanical drainage of lymphoedema, may delay the development of elephantiasis and help people to continue to lead an active life.

\section{Acknowledgements}

We thank Dr C. P. Ramachandran and Dr E. A. Ottesen (WHO, Geneva, Switzerland) for their support and helpful comments, and Dr P. Kumaran (Government General Hospital, Madras, India) for technical assistance.

\section{References}

Beaver, P. C., Jury, R. C. \& Cupp, E. W. (1984). Clinical Parasitology, 9th edition. Philadelphia: Lea \& Febiger, pp. 680-695.

Case, T. (1991). Vascular abnormalities in experimental and human filariasis. Lymphology, 24, 174-183.

Casley-Smith, J. R. (1985). Tissue changes in high protein oedemas. In: Lymphatic Pathology and Immunopathology in Filariasis. Report of the Twelfth Meeting of the WHO Scientific Working Group on Filariasis. Geneva: World Health Organization, pp. 23-24.

Casley-Smith, J. R. (1993). Treatment of filarial lymphoedema and elephantiasis with 5,6-benzo-alpha-pyrone (coumarin). British Medical Fournal, 307, 1037-1041.

Champion, R. H. (1979). Disorders of lymphatic vessels. In:
Textbook of Dermatology, Rook, A., Wilkinson, D. S. \& Ebling, F. (editors). London: Blackwell, pp. 1103-1105.

Edwards, E. A. (1979). Cutaneous changes in peripheral vascular disease. In: Dermatology in General Medicine, Fitzpatrick, T. B. (editor). New York: McGraw Hill, pp. 1376-1379.

Kar, S. (1990). Tissue tonometry: a useful tool for assessing filarial lymphoedema. Lymphology, 25, 55-61.

McGregor, A. (1994). Washing off elephantiasis. Lancet, 344, 121.

Mortimer, P. (1990). Lymphatics. In: Recent Advances in Dermatology, Champion, R. H. \& Pye, R. J. (editors). Edinburgh: Churchill Livinsgtone, pp. 175-192.

Murdoch, M. E., IIay, R. J., Mackenzie, C. D., Williams, J. F., Ghalib, H. W., Cousens, S., Abiose, A. \& Jones, B. R. (1993). A clinical classification and grading system of the cutaneous changes in onchocerciasis. British fournal of Dermatology, 129, 260-269.

Olsewski, W. L. (1991). Clinical picture of lymphoedema. In: Lymph Stasis-Pathophysiology, Diagnosis and Treatment, Olsewski, W. L. (editor). Boca Raton, Florida: CRC Press.

Olsewski, W. L.. Jamal, S., Manokaran, G., Lukomska, U. \& Kubicka, U. (1993). Skin changes in filarial and non-filarial lymphoedema of the lower extremities. Tropical Medicine and Parasitology, 44, 40-44.

Ottesen, E. A. (1985). Efficacy of diethylcarbamazine in eradicating infection with lymphatic-dwelling filariae in humans. Review of Infectious Diseases, $7,341-355$.

Ottesen, E. A. (1992). Infection and disease in lymphatic filariasis: an immunological perspective. Parasitology, 104, S71-S79.

Partono, F. (1987). The spectrum of disease in lymphatic filariasis. In: Filariasis, Ciba Foundation Symposium no. 127, pp. $15-31$.

Piessens, W., Wadee, A. \& Kurniawan, L. (1987). Regulation of immune responses. In: Filariasis, Ciba Foundation Symposium no. 127, pp. 164-173.

Pillar, N. (1990). Macrophage and tissue changes in the developmental phases of secondary lymphoedema and during conservative therapy with benzopyrone. Archives of Histology and Cytology, 53S, 209-218.

Richards, R. (1981). Verrucous and elephantoid lymphoedema: morphologic spectrum and terminology. International Journal of Dermatology, 20, 177-187.

Ryan, T., Mortimer, P. S. \& Jones, R. L. (1986). Lymphatics of the skin neglected but important. International fournal of Dermatology, 25, 411-419.

Sengupta, G., Mohangupta, T. \& Sen, P. (1986). Immunodiagnosis of filariasis. Fournal of Tropical Medicine and Hygiene, 89, 313-317.

WHO (1992). Lymphatic filariasis: the disease and its control. Fifth report of the WHO Expert Committee on Filariasis. Geneva: World Health Organization, Technical Report Series, no. 821.

WHO (1993). Lymphatic filariasis: diagnosis and pathogenesis. Update. Bulletin of the World Health Organization, 71, 135-141.

Received 17 June 1996; revised 25 Fuly 1996; accepted for publication 25 fuly 1996 